\title{
NOTAS METODOLÓGICAS
}

\author{
Maria Helena Machado ${ }^{1}$
}

\section{INTRODUÇÃO}

A construção de um projeto de pesquisa a partir de uma demanda específica, como a requerida pelo Conselho Federal de Enfermagem (Cofen) à Fundação Oswaldo Cruz (Fiocruz) para a realização da Pesquisa Perfil da Enfermagem no Brasil, requer longa negociação quanto aos objetivos, abrangência e, consequentemente, a metodologia a ser adotada.

Desta forma, foi construído o Projeto de Pesquisa Perfil da Enfermagem no Brasil, objeto do Convênio no 02/201l entre a Fiocruz e o Cofen. Posteriormente, por necessidade de prorrogação de prazo para finalização da pesquisa, foi assinado o Termo Aditivo ao Convênio no 02/2011 em agosto de 2013.

Várias foram as versões preliminares de anteprojetos, buscando aproximar os objetivos propostos. Ressalta-se que todas as versões, tanto do projeto quanto do instrumento de coleta de dados (questionário), foram construídas de forma coletiva, ouvindo e incorporando as sugestões de todas as instituições envolvidas.

O objetivo central da pesquisa foi traçar o Perfil da Equipe de Enfermagem no Brasil, analisando a situação atual da enfermagem no país nos seus diversos aspectos, buscando conhecer a sua dinâmica no recente contexto socioeconômico e político brasileiro.

Buscou também desenhar os perfis profissionais dos enfermeiros, auxiliares e técnicos de enfermagem, considerando as caracteristicas socioeconômicas, de formação e desenvolvimento profissional, de inserção no mercado de trabalho e de sua participação sócio-política, bem como analisar a dinâmica atual do mercado de trabalho de enfermagem e, por fim, apontar e analisar tendências e perspectivas da enfermagem hoje no Brasil.

Também é relevante elucidar que o projeto sofreu alteração e ajustes técnicos após o pré-teste, recebendo tratamento da área de TI, para adequação ao SisPerfil, quando da entrada dos dados no Sistema de Informação.

Após o pré-teste, o questionário passou a ter 7 Blocos, como segue:

Bloco 1 - Identificação socioeconômica

Bloco 2 - Formação profissional (enfermeiros)

Bloco 3 - Formação profissional (auxiliares e técnicos de enfermagem)

Bloco 4 - Acesso à informação técnico-científica

Bloco 5 - Mercado de trabalho

Bloco 6 - Satisfação no trabalho e relacionamento

Bloco 7 - Participação sócio-política

O projeto foi submetido e aprovado pelo Comitê de Ética e Pesquisa (CEP) da Escola Nacional de Saúde Pública Sérgio Arouca, recebendo o número: Protocolo de Pesquisa - CEP-Ensp- No. 09/10. CAAE- 0009.0.031.000.
A realização da pesquisa ficou a cargo da Fiocruz, sob a responsabilidade do Núcleo de Estudos e Pesquisas em Recursos Humanos em Saúde (NERHUS) da Escola Nacional de Saúde Pública Sérgio Arouca, sob a coordenação geral da pesquisadora Maria Helena Machado.

A pesquisa é fruto de uma grande parceria entre o Cofen e a Fiocruz, tendo apoio de diversos organismos e entidades: Ministério da Saúde, por meio do Departamento de Gestão e da Regulação do Trabalho em Saúde (DEGERTS/SGTES), Federação Nacional dos Enfermeiros (FNE), Associação Brasileira de Enfermagem (ABEn), Confederação Nacional dos Trabalhadores da Seguridade Social (CNTSS), Confederação Nacional dos Trabalhadores da Saúde (CNTS) e da Associação Nacional dos Auxiliares e Técnicos de Enfermagem (ANATEN). Contou ainda com o apoio da Rede ObservaRH e da Organização Panamericana de Saúde - OPAS.

\section{SOBRE A AMOSTRA E DESENVOLVIMENTO PROPRIAMENTE DITO DA PESOUISA}

A pesquisa Perfil da enfermagem no Brasil é um estudo transversal, cuja população alvo é constituida por todos os enfermeiros, técnicos e auxiliares de enfermagem do Brasil, que possuem registro ativo no Cofen. $\mathrm{O}$ estudo tem representatividade nacional, sendo capaz de gerar resultados para cada unidade da federação.

Quando do início de fato da pesquisa, em meados de 2012, os dados foram atualizados para o ano base ${ }^{(1)}$. Após ajustes metodológicos e tratamento estatístico, a amostra se conformou em um total de 35.916 individuos para um universo de 1.545 .102 profissionais, entre enfermeiros, técnicos e auxiliares de enfermagem

Para definição da amostra, foi utilizada 50\% (para enfermeiros e auxiliares/técnicos de enfermagem), o que maximizou a variância.

Observou-se também: a) universos de enfermeiros e de auxiliares/técnicos de enfermagem, separadamente; b) universos de cada unidade da federação; c) população de profissionais residentes na capital e nos interiores; d) idade/tempo de formado, permitindo correlacionar idade com proporcionalidade de homens e mulheres no contingente de enfermagem.

O tamanho da amostra foi calculado para se obter uma precisão de 4,5\% e um nivel de significância de $95 \%$. Utilizou-se uma proporção de $50 \%$ para maximizar a variância e, consequentemente, o tamanho da amostra.

Registre-se que, para obter o perfil da corporação de enfermagem em todos os estados e regiões do país, se procedeu à definição de amostras individuais para cada unidade da federação, considerando capital e interior. Portanto, a abrangência da pesquisa atingiu todas as regiões, todos os estados, capitais e aproximadamente metade de 
todos os municípios brasileiros, constituindo-se, assim, em uma das maiores e mais abrangentes pesquisas de área realizadas no país e na América Latina.

Para a pesquisa de campo, foram confeccionados 60.000 questionários, com vistas ao possivel reenvio, aplicação dos mesmos em eventos e locais específicos em cada estado, perdas, dentre outros.

O indice de resposta nacional atingiu $83,2 \%$, portanto, indice bastante elevado para essa modalidade de pesquisa e metodologia adotadas. Registrou-se $15,7 \%$ de perdas (questionários) e apenas $12,6 \%$ de recusas. A proporção de recusas foi estimada com base nos questionários devolvidos e com indicação de recusa por parte do respondente. Optou-se por utilizar para todas as UFs, o valor da moda de distribuição desta proporção, considerando que a UF que apresentou maior estimativa, foi a que melhor captou esta proporção entre os pesquisados, tendo em vista que nem todos os questionários cujo entrevistado recusou-se a responder, foi devolvido para a equipe da pesquisa.

O processo amostral, com base nos registros do Cofen, levou os Conselhos Regionais a realizarem uma revisão detalhada de seus cadastros, o que ocasionou uma correção dos totais populacionais inicialmente definidos para a pesquisa. Por este motivo, o processo de calibração foi baseado na nova distribuição de profissionais de enfermagem fornecida pelo Cofen, de modo que as estimativas da pesquisa fossem coerentes com esta população.

O peso final, após a calibração, foi calculado da seguinte forma:

$$
W_{h}^{*}=W_{h} * \frac{N_{h}^{a}}{N_{h}^{*}}
$$

Onde,

${ }^{w *} h$ é o peso do profissional de enfermagem no estrato $h$ após a calibração;

$W_{h}$ é o peso do profissional de enfermagem no estrato $h$;

$\mathrm{N}_{\mathrm{h}}{ }_{\mathrm{h}}$ é o número de profissionais de enfermagem no estrato $\mathrm{h}$ (população) atualizado pelo Cofen após a seleção da amostra;

$\mathrm{N}^{*} \mathrm{~h}$ é o tamanho da amostra expandida, considerando a probabilidade de seleção e a taxa de resposta.

Portanto, o universo expandido e calibrado da população pesquisada passou a ser: 1.804.535, contudo, mantendo a mesma proporcionalidade entre categorias e estados da federação.

Importante registrar também que antes do envio dos questionários pelos Correios, foi realizada em todo o país uma campanha nacional de sensibilização junto aos profissionais de enfermagem para que o respondessem. Para isso, foram confeccionados cartazes, panfletos explicativos, filipetas, adesivos para carros, etc., que foram distribuídos em todos os locais de trabalho pelos coordenadores estaduais. Da mesma forma, foram utilizados os meios de comunicação televisiva, escrita e falada, tendo os coordenadores estaduais e a direção dos Corens, grande participação. Utilizou-se também as redes sociais para divulgação da pesquisa, tais como facebook, site da pesquisa, sites do Cofen e dos Conselhos Regionais.

Após esse processo de ampla divulgação na imprensa, nos locais de trabalho e nas universidades e procedida a etiquetagem e envelopamento, realizados pela equipe técnica da Fiocruz, os questionários foram enviados pelos Correios, junto com um envelope para resposta com porte pago, totalizando 35.916 respondentes.
O trajeto dos questionários, portanto, seguiu a lógica: a) Etiquetagem e envelopamento pela equipe da Fiocruz; b) Envio aos respondentes, quer para sua residência e/ou para endereço de correspondência informado pelo próprio profissional ao Coren de seu estado; c) Após recebimento e preenchimento, devolução do mesmo pelo respondente, colocando o questionário em qualquer caixa de correios de sua cidade; d) Os questionários respondidos eram devolvidos (com porte pago) ao Cofen em Brasilia; e) Após a chegada ao Cofen, estes eram transportados por profissional da equipe da Fiocruz, residente em Brasilia, até a regional da Fiocruz, para conferência, separando-se então os questionários por estado e, posteriormente, envio, para a sede da pesquisa no Rio de Janeiro.

Com vistas a operacionalização da pesquisa nos estados, a coordenação geral optou por selecionar por tempo determinado, profissionais (enfermeiros) com a função de 'coordenação estadual', otimizando assim o complexo trabalho da pesquisa de campo a ser realizada em todo o país. Concomitantemente, foram criadas as coordenações regionais, com técnicos experientes em pesquisa, com a função de supervisionar os trabalhos de pesquisa de campo nos estados das respectivas regiões. Estes coordenadores integraram, temporariamente, a equipe técnica da Fiocruz ${ }^{3}$.

O indice de devolução de questionários por endereço desatualizado foi relativamente alto na maioria dos estados. Com a ajuda dos coordenadores estaduais, foi possivel rever os endereços, atualizando-os, e reenviá-los. Essa busca ativa da amostra em cada estado foi fundamental para o melhor desempenho da pesquisa.

Paralelamente, por orientação da coordenação geral, tendo a supervisão do coordenador regional, o coordenador organizou e coordenou a realização de eventos específicos. Nestes eventos, o próprio coordenador aplicava questionários aleatoriamente, tomando como base as variáveis determinantes da amostra, quais sejam: categoria profissional (enfermeiro, auxiliar e técnico de enfermagem). idade, sexo e municipio de residência. Estes questionários passaram a fazer parte do Banco de Amostra e, posteriormente, foram usados na substituição da amostra original, guardando sempre a proporcionalidade e a tipologia da amostra.

As atividades da pesquisa de campo foram realizadas no periodo compreendido ente junho-dezembro de 2012 (em alguns casos até meados de 2013).

Como recurso metodológico adicional, as coordenações regionais e estaduais, juntamente com a equipe técnica da Fiocruz, participaram dos grandes eventos da categoria, realizados no período da pesquisa de campo, objetivando a divulgação e aplicação de questionários aos participantes, aleatoriamente.

Concomitantemente, foi disponibilizado na web, questionário on line (SisPerfil) pelo endereço www.perfildaenfermagem.com.br, tendo acesso distinto dois universos de profissionais:

a) Profissionais de enfermagem selecionados na amostra;

b) Todos os profissionais de enfermagem - enfermeiros, auxiliares e técnicos de enfermagem - que, voluntariamente, desejassem responder ao questionário.

A modalidade "a" (restrita) - profissionais da amostra - tinha acesso ao questionário mediante o seguinte processo: 1) para se logar, ele deveria digitar o número de seu registro no Coren; 2) o sistema verificava imediatamente se o profissional estava na amostra; 3) se positivo, ele então teria acesso ao questionário; 4) uma vez respondido, este questionário passava a integrar o Banco de Dados 
on line da pesquisa (SisPerfil)

Já no caso "b", ou seja, o acesso voluntário, o profissional preencheria um cadastro e ao final do cadastramento, este receberia um e-mail dando o login e a senha para acessar o questionário. Uma vez preenchido, o questionário iria para o Banco de Amostra on line e, posteriormente, seriam usados em substituições, nos moldes já descritos anteriormente, guardando sempre a proporcionalidade e a tipologia da amostra original.

O SisPerfil foi desenvolvido pela Fiocruz para dar acesso on line à pesquisa (questionário) e, posteriormente, ser a ferramenta de processamento de dados para a construção do Banco de Dados da Pesquisa Perfil da Enfermagem no Brasil.

Relevante afirmar que o SisPerfil é um produto da Pesquisa Perfil da Enfermagem no Brasil, com características fundamentais: um Banco de Dados público, de livre acesso e de fácil manuseio e utilização.

\section{NOTAS FINAIS}

Finalizado o período estimado da pesquisa de campo, bem como dos contratos de bolsas correspondentes dos coordenadores estaduais, foi feito um balanço dos resultados obtidos no período. A partir desse balanço, traçou-se a 2 2 etapa da pesquisa de campo, ou seja, a pesquisa complementar nos grandes empregadores hospitalares, nas capitais de todos os estados, considerando a natureza administrativa da Instituição - a) hospital público; b) hospital privado; c) hospital filantrópico; e d) hospital universitário (federal). Obedeceu-se aos procedimentos exigidos pelo Comitê de Ética em Pesquisa da Ensp e dos Comitês de Ética de Pesquisa dos hospitais, quando existiam e em todos os casos, se procedeu a autorização por escrito da direção do hospital, permitindo o livre acesso às dependências do estabelecimento. Contudo, sempre, se respeitou os princípios da ética e do compromisso com o sigilo, respeito e direito de recusa do respondente

Nestes hospitais, foram aplicados os questionários e, adicionalmente, um pequeno formulário com perguntas específicas quanto ao trabalho, propriamente dito, na Instituição. Também nesse caso, a aplicação dos questionários se deu de forma aleatória, considerando-se as variáveis fundamentais da amostra: categoria profissional, sexo, idade, ano de conclusão do curso.

Uma vez preenchido, este passaria a fazer parte também do Banco de Amostra, sendo posteriormente usado nas substituições, nos moldes já descritos anteriormente, guardando sempre a proporcionalidade e a tipologia da amostra original.

Fundamental esclarecer que: primeiro, no preenchimento do questionário por profissional voluntário, foram respeitados os princípios da ética em pesquisa, sendo informado ao respondente a plena liberdade de recusa de preenchimento, sem qualquer constrangimento ao mesmo; segundo, toda essa $2^{\text {a }}$ etapa da pesquisa de campo foi realizada por nossa equipe técnica em colaboração com os ex-coordenadores estaduais, estes já sem qualquer vínculo formal com a Fiocruz, ou seja, sem contrato de bolsa, apenas e principalmente, pelo compromisso e interesse em construir o perfil da sua profissão! Nesta etapa, a equipe da Fiocruz recebeu total apoio da direção dos Corens colocando toda a infraestrutura disponivel e que se fizesse necessária.

Após concluida essa 2a etapa, foi dada como encerrada a pesquisa de campo propriamente dita.

Concluída a pesquisa de campo, procedeu-se à checagem dos questionários, digitação dos mesmos, conferência e ajustes do Banco de dados (SisPerfil) e confecção dos planos tabulares. Com base nos planos tabulares foram construidas as tabelas, gráficos e quadros a serem analisados pela equipe técnica. Relevante apontar que estimase um total de 20.000 tabelas básicas, 15.000 gráficos e dezenas de quadros, que compõe o Relatório final da pesquisa. Observa-se que foi produzido o Perfil da Enfermagem no Brasil considerando os três universos da pesquisa: Equipe de Enfermagem; Enfermeiros: Auxiliares e Técnicos de Enfermagem, nos 27 estados da federação e Brasil e Regiões, somando assim, 28 volumes, o Relatório Final.

Em maio de 2015, como previsto, ocorreu, em Brasilia, o lançamento nacional dos dados, com ampla cobertura da imprensa nacional. Em seguida, por decisão política do Cofen e apoiada pela Fiocruz, foram realizados os lançamentos regionais, cobrindo todo o território nacional. Estes lançamentos regionais tiveram como objetivo central a democratização das informações em cada estado e a possiblidade de dialogar com os trabalhadores da enfermagem, as lideranças locais e os gestores estaduais e municipais. Estiveram presente, em todos os 27 estados, a equipe técnica da Fiocruz e a direção do Cofen, que, juntos, debateram e possibilitaram a divulgação massiva dos dados.

Concluindo, não há dúvida de que essa investigação constitui a maior e mais importante pesquisa sobre um contingente de trabalhadores da área da saúde, o que significa hoje quase dois milhões de profissionais na base do Cofen, constituindo-se na maior e mais completa pesquisa sobre a Enfermagem na América Latina e certamente no mundo.

Será, com certeza, um marco na história do SUS e especialmente na Enfermagem brasileira, contribuindo assim para a formulação de políticas públicas mais adequadas a esse tão importante contingente de trabalhadores e trabalhadoras essenciais ao Sistema de Saúde do Brasil.

REFERÊNCIAS

1. Conselho Federal de Enfermagem [homepage na internet]. Enfermagem em números [acesso em 10jun 2012]. Disponivel em: www.cofen.gov.br/ enfermagem-em-numeros.

Recebido: 30/11/2015

Aceito: 22/02/2016

8 | Enferm. Foco 2016; 7 (ESP): 06-08 